\title{
A utilização do beergame por alunos de um curso técnico integrado em
}

\section{administração}

\author{
The use of beergame by students of an integrated technical course in administration \\ El uso de beergame por alumnos de curso técnico integrado en administración
}

Recebido: 09/03/2021 | Revisado: 16/03/2021 | Aceito: 18/03/2021 | Publicado: 26/03/2021

Euclides Brandão Maluf
ORCID: https://orcid.org/0000-0002-1655-8784
Instituto Federal de Educação, Ciência e Tecnologia de Minas Gerais, Brasil
E-mail: euclidesmaluf@gmail.com
Amanda Camilo Graciano
ORCID: https://orcid.org/0000-0001-7952-8307
E-mail: ac.graciano29@gmail.com
Instituto Federal de Educação, Ciência e Tecnologia de Mina Gerais, Brasil
Dandara Lorrayne do Nascimento
ORCID: https://orcid.org/0000-0003-1169-1575
Instituto Federal de Educação, Ciência e Tecnologia de Minas Gerais, Brasil
E-mail: dandaralno@gmail.com

\section{Resumo}

A aplicação da informática na área da educação sempre foi um fator preponderante na área da educação, pois proporciona aos professores métodos de ensino ampliados e aos alunos mais oportunidades de aprendizagem. $\mathrm{O}$ presente estudo tem como proposta analisar o uso da tecnologia aplicada em sala de aula, mediante a utilização do BeerGame, com alunos do terceiro ano do curso técnico integrado e relacioná-los ao processo de ensino e aprendizagem, possibilitando uma visão mais atraente de forma dinâmica, facilitando a linguagem e a compreensão do aluno. Sendo assim, este artigo considera que através dos recursos tecnológicos apresentados em sala de aula podem auxiliar no aprendizado, facilitando a compreensão e colocando o aluno em possíveis situações reais do cotidiano. Dentre os principais benefícios observados que o jogo pode proporcionar para os professores, se destacam a possibilidade de exibir e explicar vários conceitos de negócios além de ajudar a integração de um conceito teórico abstrato com prática; já para os alunos a diversão do jogo promove a aprendizagem e essa experiência se torna mais eficaz. Outro ponto chave observado foi a compreensão sistemática de conceitos complexos como finanças, economia, gestão, entre outros.

Palavras-chave: Tecnologias na educação; Ensino e aprendizagem; Educação básica.

\begin{abstract}
The application of information technology in the area of education has always been a major factor in the area of education, as it provides teachers with expanded teaching methods and students with more learning opportunities. This study aims to analyze the use of technology applied in the classroom, through the use of BeerGame, with third year students of the integrated technical course and relate them to the teaching and learning process, enabling a more attractive view in a way dynamics, facilitating the student's language and understanding. Therefore, this article considers that through the technological resources presented in the classroom, they can assist in learning, facilitating comprehension and placing the student in possible real everyday situations. Among the main observed benefits that the game can provide for teachers, we highlight the possibility of displaying and explaining various business concepts in addition to helping the integration of an abstract theoretical concept with practice; for the students, the fun of the game promotes learning and this experience becomes more effective. Another key point observed was the systematic understanding of complex concepts such as finance, economics, management, among others.
\end{abstract}

Keywords: Technologies in education; Teaching and learning; Basic education.

\section{Resumen}

La aplicación de la tecnología de la información en el área de educación siempre ha sido un factor importante en el área de educación, ya que brinda a los maestros métodos de enseñanza ampliados y a los estudiantes más oportunidades de aprendizaje. El presente estudio tiene como objetivo analizar el uso de la tecnología aplicada en el aula, a través del uso de BeerGame, con los alumnos de tercer año del curso técnico integrado y relacionarlos con el proceso de enseñanza y aprendizaje, posibilitando una visión más atractiva en un dinámica de caminos, facilitando el lenguaje y la comprensión del alumno. Por ello, este artículo considera que a través de los recursos tecnológicos presentados en el aula, pueden ayudar en el aprendizaje, facilitando la comprensión y colocando al alumno en posibles 
situaciones reales del día a día. Entre los principales beneficios observados que el juego puede brindar a los docentes, destacamos la posibilidad de mostrar y explicar diversos conceptos empresariales además de ayudar a la integración de un concepto teórico abstracto con la práctica; para los estudiantes, la diversión del juego promueve el aprendizaje y esta experiencia se vuelve más efectiva. Otro punto clave observado fue la comprensión sistemática de conceptos complejos como finanzas, economía, gestión, entre otros.

Palabras clave: Tecnologías en educación; Enseñando y aprendiendo; Educación básica.

\section{Introdução}

O avanço tecnológico atual na educação caracteriza-se, dentre outras coisas, pela utilização da informática como um recurso didático relevante. Esse uso, como instrumento propiciador de aprendizagem, vem aumentando de forma cada vez mais rápida na sociedade (Toledo, 2014).

As tecnologias, entretanto, devem ser utilizadas de acordo com os propósitos educacionais da escola, mediante estratégias adequadas para propiciar ao aluno a aprendizagem, não podendo ser regida como a informatização do ensino, que reduz as tecnologias a meros instrumentos para instruir o aluno (Bernardi, 2010).

Neste cenário e com todos os recursos computacionais existentes, encontramos alguns softwares educacionais que podem ser utilizados como apoio ao trabalho docente, enriquecendo sua prática pedagógica e proporcionando momentos de motivação e grande interesse dos alunos, uma vez que estes vêm desempenhando cada vez mais um papel relevante como ferramenta educativa (Filho \& Matos, 2010).

A utilização de um software educativo em sala de aula desperta no aluno o desejo pelo estudo, sendo este um meio diferente de educar e de chamar a atenção do aprendiz (Cavalcanti, et. al, 2017).

De acordo com Scattone e Masini (2007) o software educativo trata-se de um recurso psicopedagógico interativo, integrado aos currículos escolares desde a educação infantil e, por isso, fazem-se necessários estudos sobre a sua utilização e se esta ocorre com propriedade.

Considerando os aspectos expostos, este estudo vem como uma alternativa para utilizar a tecnologia na área pedagógica, a fim de tornar as aulas mais produtivas, dinâmicas e trazer uma melhor temática tanto para os professores quanto para os alunos.

A proposta deste trabalho consiste em um estudo feito com estudantes do curso Técnico Integrado em Administração de um instituto federal, mediante a utilização do software educativo BeerGame e, a partir disso, foi analisado o uso desta tecnologia em sala de aula, avaliado o comportamento, a atratividade, compreensão e entendimento dos alunos pelo assunto abordado.

\section{Revisão de Literatura}

\subsection{A educação e a Tecnologia}

De acordo com Leite (2010), a utilização de ferramentas tecnológicas voltadas à educação teve início da década de 60. Neste período, o maior objetivo era inserir o Brasil no mercado econômico mundial como produtor e consumidor de bens.

Nesse contexto surge a área de Tecnologia Educacional (TE) que, dentro da visão tecnicista, significa dar ênfase aos meios na educação sem questionar suas finalidades. A utilização da tecnologia na escola foi associada a uma visão limitada de educação, baseada em fundamentos teóricos e ideológicos externos (Leite, 2010).

Na década de 80 a tecnologia Educacional passou a ser interpretada de maneira mais crítica e eficaz Ressalta-se que as TE exigem grande domínio do docente, frente aos conteúdos ministrados.

O domínio do professor deve se concentrar no campo crítico e pedagógico, pois assim ele evita ser vítima de imposição tecnológica na sala de aula e pode ter a opção de integrar ou não a tecnologia em seu currículo, de acordo com os 
objetivos e competências a serem desenvolvidos, e ainda escolher o momento apropriado para fazê-lo. O professor não pode perder a dimensão pedagógica (Leite, 2010).

Nota-se, contudo, que mesmo diante de tantas vantagens oferecidas pelo uso das tecnologias digitais e do reconhecimento das mesmas como fator de mudança dos processos de ensino e aprendizagem, ainda, existe certa resistência por parte de alguns professores em aproveitar suas potencialidades pedagógicas (Brown, Collins \& Duguid, 1989). Dentre os diversos fatores de resistência, que dificultam a integração pedagogicamente adequada das Tecnologias da Informação e Comunicação (TIC's) ao processo educativo, encontram-se a formação inadequada ou insuficiente do professor e o desconhecimento de boas estratégias didáticas (Caetano, 2012 \& Dennemann, 2013 como citado em Batista, 2016).

Nesta perspectiva, apesar de existir investimento e recursos disponíveis para utilização das tecnologias na sala de aula, um estudo feito por Carmo, Paciulli e Nascimento (2020) com 327 professores da rede federal evidenciou que um grande número de professores se sente despreparados para usá-las adequadamente ou não se dispõe a alterar sua tradicional metodologia de ensino (Nascimento, 2013 como citado em Sales \& Batista, 2016).

Para mudar esse quadro, é preciso que os docentes conheçam ferramentas, entendam a cultura em que seus alunos estão inseridos e, com base nos novos conhecimentos, revejam suas práticas pedagógicas (Gabriel, 2013).

\subsection{A Tecnologia Aplicada em Sala de Aula}

De acordo com Tajra (2001), nos anos 80 os países desenvolvidos transformaram a inclusão dos computadores em sala de aula como uma necessidade de uso igual ao caderno e livros, uma ferramenta primordial.

Em 1983, 53\% das escolas dos Estados Unidos já utilizavam computadores com grande apoio de empresas privadas que atuavam nesta área. A França, por meio do Plano "Informática para Todos", e a Espanha, por meio do Projeto Atenea, estimularam a formação em informática para capacitação docente (Tajra, 2001, p. 29).

Dentre os diversos benefícios, Batista e Baldissera (2011) destacam que o contato orientado do estudante com o computador em situações de ensino-aprendizagem contribui para o desenvolvimento cognitivo e intelectual, em especial no que diz respeito ao raciocínio lógico e formal, a capacidade de pensar e sistematizar, a habilidade de inventar ou resolver problemas.

Dessa forma, o professor que associa as TIC's aos métodos ativos de aprendizagem desenvolve a habilidade técnica relacionada ao domínio da tecnologia e, sobretudo, articula esse domínio com a prática pedagógica e com as teorias educacionais que o auxiliem a refletir sobre a própria prática e a transformá-la, visando explorar as potencialidades pedagógicas das TIC em relação à aprendizagem e à consequente constituição de redes de conhecimentos (Almeida, 2008 como citado em Batista \& Baldissera, 2011).

Diversos são os softwares que podem ser utilizados como recursos educacionais. Disciplinas como a Matemática, por exemplo, pode ser utilizado o Excel, que possui recursos como construção de gráficos e planilhas. Na disciplina de Português, o docente pode envolver atividades como publicações em blogs. Tajra (2001) afirma que o uso da tecnologia auxilia professores a buscar a inovação trazendo para sala de aula um conteúdo atualizado e que atrai sempre a atenção do aluno para as aulas. Outras disciplinas, como a Geografia, podem fazer grandes buscas através da internet no Google Maps, mostrando para o aluno um universo com localizações em tempo real.

Além dos computadores, podem ser utilizados recursos tecnológicos como televisão, rádio, jornais, revistas, DVD’s e data shows como auxílio em sala de aula a fim de promover discussões, debates, realizar jogos, fazendo com que o professor consiga apresentar ao aluno uma visão diferente e uma aula não tradicional. 


\subsection{O BeerGame}

Durante décadas, o BeerGame foi jogado em workshops e reuniões corporativas, bem como utilizado para estudos voltados à administração, negócios ou aulas de modelagem, tendo como objetivo apresentar aos profissionais e alunos algumas lições importantes sobre sistemas dinâmicos complexos. Apesar de possuir uma interface simples, o jogo é capaz de fornecer lições importantes e duradouras aos participantes sobre os princípios básicos dos sistemas (Martinez-Moyano, Rahn \& Spencer, 2005, Pinheiro et al., 2016).

Projetado para representar uma cadeia de suprimentos simplificada, o jogo tem sido amplamente comentado nas configurações de cadeia de suprimentos e gerenciamento corporativo e se tornou a ferramenta educacional amplamente usada para engajar novatos na dinâmica do sistema e encorajá-los a adotar uma abordagem orientada a sistemas, ou seja, dinâmica do sistema dentro de uma perspectiva não linear (Bellomusto, 2018).

No tocante à sua caracterização, o BeerGame retrata um sistema de distribuição de produção caracterizado por um estoque, destinado a cada um dos quatro respectivos participantes: fábrica ou cervejaria, distribuidor, atacadista e varejista dispostos em uma cadeia de distribuição linear (Silva, 2013).

Moedas ou chips de plástico representam caixas de cerveja. Os fluxos que influenciam cada um dos estoques incluem o fluxo de informações de pedidos do varejista para a cervejaria e o transporte físico de mercadorias de um estoque para o outro através da cadeia de abastecimento, incluindo um atraso de duas semanas (Pinheiro et al., 2016).

De acordo com Souza (2019) os elementos exógenos ao sistema são os pedidos do consumidor, entregues por meio de um baralho de cartas na extremidade do varejista da cadeia e as entradas para a produção de estoque do cervejeiro, ou seja, o fornecimento de chips aos quais o cervejeiro tem acesso. A Figura 1 representa o gerenciamento da cadeia de suprimentos.

Figura 1 - Gerenciamento da cadeia de suprimentos.

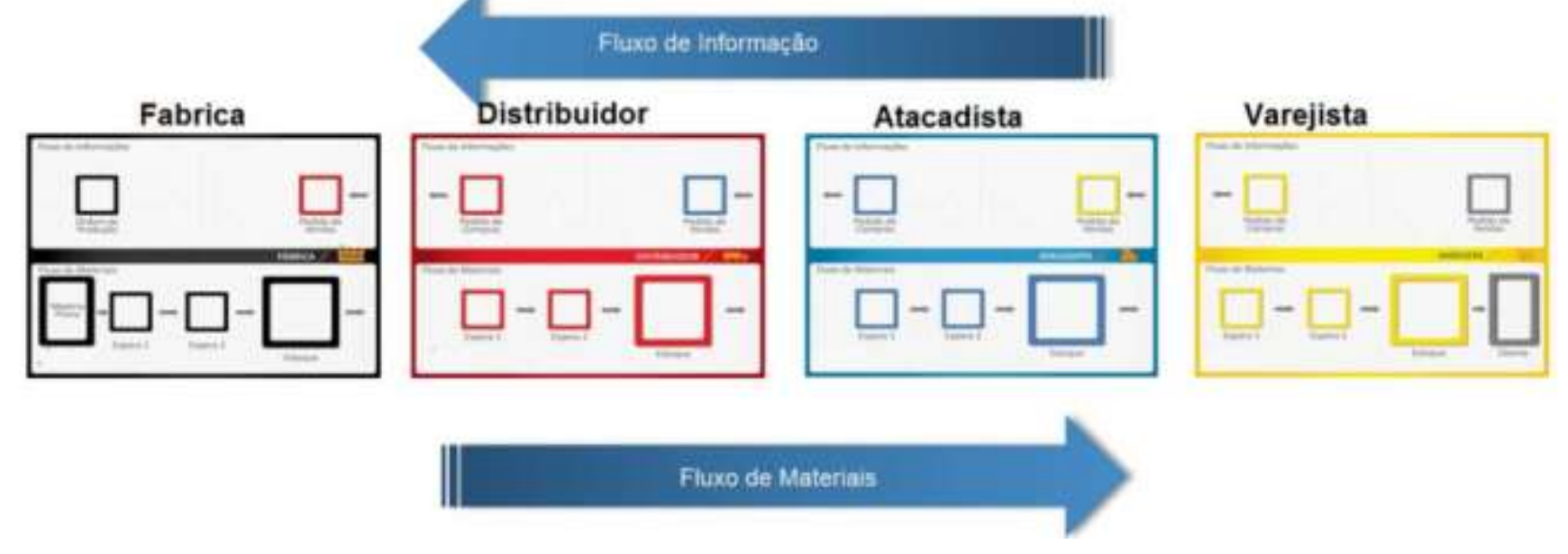

Fonte: https://www.epcs.com.br/servico/beer-game

A dinâmica segue o exposto pela Figura 1, isto é, para cada semana do jogo, os clientes compram do varejista, que então faz o pedido do atacadista, e este por sua vez, faz o pedido do distribuidor, que então faz o pedido da fábrica, que então produz caixas adicionais de cerveja para atender à demanda prevista.

Segundo Lira (2020), cada participante gerencia seus respectivos estoques por meio da previsão de demanda, que é informada pelos pedidos de seus clientes, situados um degrau abaixo na cadeia de suprimentos e fazendo pedidos aos seus fornecedores um degrau acima na cadeia de suprimentos. No entanto, apenas o varejista pode ver a demanda real dos pedidos dos clientes semana a semana.

Tal limitação de informações é ainda mais restrita, uma vez que os jogadores não têm permissão para se comunicarem 
entre si, portanto, a coordenação é impossível. Embora simplificado se comparado aos sistemas do mundo real, o jogo revela características e limitações importantes na tomada de decisão humana e os princípios dos sistemas (Lira, 2020).

\subsubsection{A Tomada de Decisão Frente às Estruturas de Sistemas Complexos}

A tomada de decisão humana em sistemas complexos foi auxiliada por simuladores de voo de gerenciamento, que permitiram que os dinamistas do sistema estudassem a tomada de decisão de um indivíduo dentro de estruturas de sistema simples, semelhantes às do BeerGame (Garcia et al., 2017).

Cunha e Lima (2004) resumiram as principais conclusões dos principais trabalhos nesta área com base nas características da complexidade do sistema: atrasos, força de feedback e mudança exógena. Em geral, a presença de atrasos de tempo, bem como a duração dos atrasos e loops de feedback mais fortes tendem a reduzir o desempenho, embora as alterações exógenas tenham se mostrado reduzidas, melhorado, ou nenhum efeito no desempenho.

Sempre que o contexto da situação de decisão muda, como no caso de suspensão do intervalo de decisão para acelerar ou desacelerar a geração de experiência; necessidade de aumentar a transparência e, portanto, o conhecimento do modelo ou tarefa sendo gerenciada; ou a natureza das informações de decisão, como interface design e tipos de feedback fornecidos ao usuário, os participantes tendem a apresentar um desempenho um pouco melhor, ou pelo menos não pior do que seu desempenho anterior sem a transparência adicional (Bellomusto, 2018).

É importante ressaltar que, as características pessoais que provavelmente afetam o desempenho, no caso de jogadores que apresentam objetivos declarados; modelo mental ou estilos cognitivos; ou o número de jogadores no simulador também mostraram resultados mistos, com desempenho aprimorado resultante de objetivos de todo o sistema e um maior grau de similaridade no participante modelo mental com a estrutura da simulação (Silva, 2016).

Avanços mais recentes na pesquisa de tomada de decisão usando simulações da tarefa BeerGame mostraram que o risco de coordenação, especialmente no que concerne ao risco de que as decisões dos indivíduos contribuam para um resultado coletivo, mas as regras de decisão seguidas por cada indivíduo não são certas, acabam contribuindo para que o efeito chicote possa ser mitigado com estoque de coordenação, mantendo estoque adicional disponível, mas com causas comportamentais da instabilidade da cadeia de abastecimento se mantendo robustas (Silva, 2013).

Garcia et al. (2017) mostraram que, devido a essa persistência de instabilidade, os indivíduos tendem a buscar estoques de segurança maiores (entesouramento) ou pedir mais do que é exigido deles. Essas respostas irracionais demostram ser desencadeadas por estressores ambientais, que sobrecarregaram as habilidades de tomada de decisão racional dos indivíduos ou quando os indivíduos aplicaram inadequadamente heurísticas de decisão incompatíveis com o desempenho eficaz no jogo.

\subsubsection{O Efeito Chicote}

O efeito chicote descreve um fenômeno observado em cadeias de distribuição multicamadas com padrões de demanda incertos e informações limitadas sobre o status nos diferentes elementos da cadeia de suprimentos (Chopra \& Meindl, 2001). Ele descreve um efeito de que as amplitudes do estoque aumentam conforme você desce na cadeia de suprimentos. É também chamado de efeito Forrester porque foi descrito pela primeira vez por Jay Wright Forrester, um professor do MIT Sloan School of Management, em seu livro Industrial Dynamics em 1961. Esses estudos inovadores foram a base do gerenciamento moderno da cadeia de suprimentos (Fioriolli \& Fogliatto, 2009).

De acordo com Bellomusto (2018) as consequências do efeito Chicote são óbvias, uma vez que levam ao aumento do estoque de segurança e, portanto, os custos de estoque, e reduzem o nível de serviço. Além disso, tende a aumentar os custos totais de transporte, uma vez que há uma falta de coordenação das políticas de transporte e gerenciamento de estoque devido à 
incapacidade de estimar com precisão os requisitos em um determinado período. Em geral, torna mais difícil gerenciar e operar o sistema com eficiência, pois os recursos disponíveis não são utilizados de forma eficiente.

Somam-se aos fatores acima citados, o fato de que muitas das distorções de informações que levaram ao efeito Chicote foram eliminadas. Na fábrica, o jogador pode ver a demanda do cliente, compará-la com o estoque total do sistema e reagir apropriadamente. Não há necessidade de tentar prever a demanda do cliente e estimar as políticas usadas para propagar a demanda em todo o sistema. Assim, erros de previsão e políticas de pedidos não servem para ocultar informações de demanda real e um custo de sistema mais baixo pode ser alcançado (Cunha \& Lima, 2004).

Nesta perspectiva, o aumento do fluxo de informação e o controle centralizado só podem ser benéficos para a operação do sistema. Na verdade, mesmo quando o controle é centralizado é difícil porque diferentes estágios da cadeia de abastecimento têm proprietários diferentes, vale a pena implementar, pois, cada etapa tem um prazo de entrega de 2 semanas para mercadorias e informações (Silva, 2013).

Assim, Pinheiro et al. (2016) destacam que, a qualidade de cada uma das políticas realizadas pelos jogadores é avaliada com base nos valores de custo do estoque. Em outros termos, os jogadores compartilham o objetivo comum de reduzir seus próprios custos de estoque e são livres para definir uma política pessoal de acordo com seu entendimento da situação e sua atitude pessoal em relação ao risco. Para apoiar a coleta e análise dos dados, cada jogador utiliza uma planilha eletrônica, que inclui dados relativos a pedidos enviados e recebidos e mercadorias.

\subsubsection{Planejamento de Capacidade e Gerenciamento de Estoque}

O planejamento de capacidade é comumente considerado uma das tarefas mais difíceis entre os jogadores. Nenhum dos participantes pode lidar com a restrição de capacidade em qualquer unidade funcional, e caso ocorra, isso pode resultar em penalidades financeiras e deterioração do desempenho do atendimento ao cliente (Titton, 2006).

De acordo com Silva (2016) a falha no planejamento da capacidade, por sua vez, resulta da falta de verificações regulares da capacidade e da previsão de demanda insuficiente. Em termos de gerenciamento de estoque, acabam ocorrendo situações de excesso de estoque e falta de estoque. Isso ocorre porque não há um sinal claro para mostrar se o nível de estoque em cada departamento é afetado pelas decisões a montante ou a jusante.

Para sanar tais falhas, o uso de relatórios do sistema Management Information Systems (MIS) ajuda os jogadores a analisar sua capacidade e situação de estoque, especialmente quando são capazes de integrar informações do cliente, como histórico de pedidos e tendências de demanda. Desta forma a adoção de uma estratégia Lean pode ser adotada com o objetivo de minimizar estoques e manter os níveis de serviço ao cliente (Silva, 2013).

\section{Metodologia}

O presente trabalho caracteriza-se como uma pesquisa qualitativa e descritiva, que utiliza de levantamento de dados primários. Para Martins e Theóphilo (2009), a pesquisa qualitativa envolve a busca de evidências que não são expressas por dados e números, mas sim por descrições, interpretações, compreensões e análise de informações, através de entrevistas, observações, análise de conteúdo e outros. Neste sentido, de acordo com Koche (2011), os métodos qualitativos são aqueles nos quais é importante a interpretação por parte do pesquisador com suas opiniões sobre o fenômeno em estudo.

Para alcançar as metas delimitadas neste trabalho, foi necessário a realização de uma pesquisa descritiva, na qual os pesquisadores realizam a descrição, registros e análises dos dados obtidos, como sugerem Pereira, Shitsuka, Pereira e Shitsuka (2018).

Tendo em vista a pandemia causada pelo COVID-19, a Organização Mundial de Saúde recomendou o isolamento social como forma de conter o vírus. Diante desse cenário e a adoção do ensino remoto, o que impossibilitou a aplicação de 
mais questionários de visitas na empresa estudada, a coleta de dados foi realizada em Dezembro de 2019 através de recursos tecnológicos e também de uma dinâmica presencial, o contato foi realizado com os representantes da organização o que garante a fidelidade das análises realizadas neste trabalho.

Como instrumento de investigação, o levantamento de dados para a presente pesquisa foi efetuado por meio de três momentos e contou com 26 participantes. Todas as três partes foram realizadas no dia 03 de dezembro de 2019 em um laboratório de informática. Cada participante teve acesso a um computador, onde foi disponibilizado o acesso ao jogo.

A primeira parte da coleta de dados consistiu na apresentação e explicação sobre o BeerGame. Foi apresentado um breve tutorial a respeito do jogo, suas características e usabilidade: "O jogo inicia-se em equilíbrio. Consumidores estão pedindo 10 caminhões de cerveja e você tem 10 caminhões em cada elo da cadeia. O jogo é simples, na segunda semana seus consumidores aumentarão seus pedidos de 10 para 15 caminhões de cerveja devido a uma campanha promocional feita pela sua empresa. Este valor ficará fixo para outras semanas. Seu objetivo é retornar o sistema ao equilíbrio, então 15 caminhões de cerveja estarão disponíveis no estoque de produtos acabados semana após semana. Você terá até 50 semanas para atingir este objetivo."

No segundo momento foi marcado pelo início do jogo. Os participantes tiveram até 50 minutos para completar as 50 rodadas e concluir o jogo. Ao final da segunda etapa, os alunos receberam um retorno sobre seu desempenho final no jogo, bem como uma apresentação de alguns pontos onde os participantes cometeram erros comprometedores durante as rodadas, assim eles puderam refletir a respeito desses pontos.

$\mathrm{Na}$ terceira etapa, os participantes receberam o questionário estruturado por e-mail e puderam se dedicar a respondêlo. Durante essa etapa, também foi realizado o fechamento da dinâmica, onde os alunos puderam tirar dúvidas e compartilhar suas experiências com os demais participantes.

Ressalta-se, que mesmo diante da necessidade de se realizar a coleta de dados por meio digital, todas as informações obtidas foram plenamente explicadas e descritas em todos os seus detalhes, não deixando espaços para dúvidas.

\section{Resultados e Discussão}

Na seção anterior foram apresentados os procedimentos metodológicos utilizados na efetivação da pesquisa. Nesta seção são apresentados os resultados obtidos junto aos participantes do estudo.

Inicialmente buscou-se conhecer o perfil dos participantes, como representa a Figura 2.

Figura 2 - Idade dos entrevistados

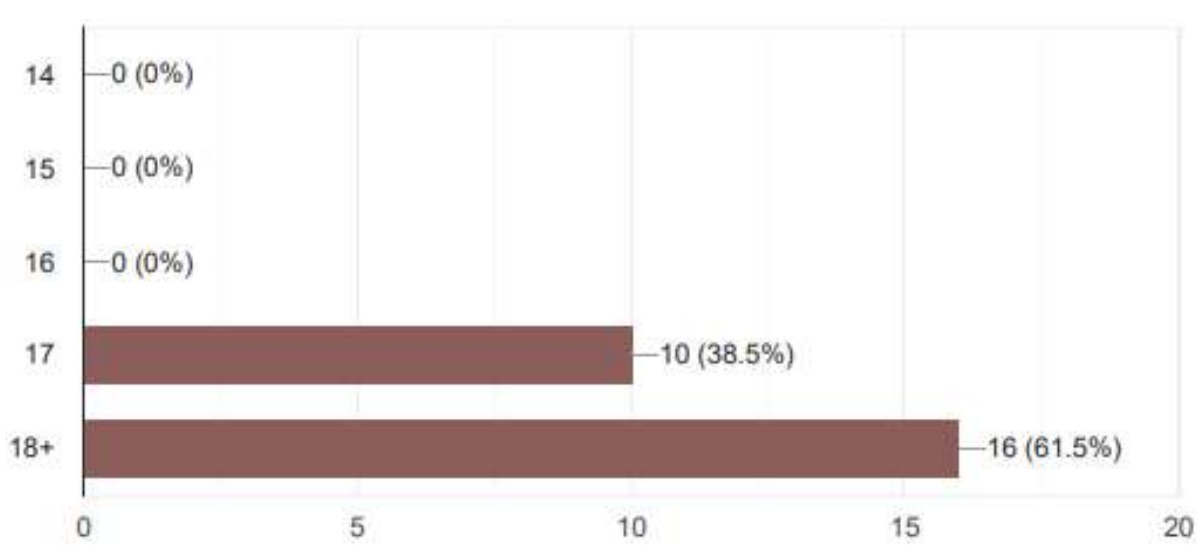

Fonte: Autores. 
De acordo com a Figura 2, 61,5\% dos estudantes que participaram do estudo estão situados na faixa etária igual ou acima de 18 anos e, 38,5\% tem 17 anos.

Após a apresentação do BeerGame, aos alunos, foi perguntado se estes sentiram-se motivados para participar da dinâmica (Figura 3).

Figura 3 - Alunos motivados a participar da dinâmica.

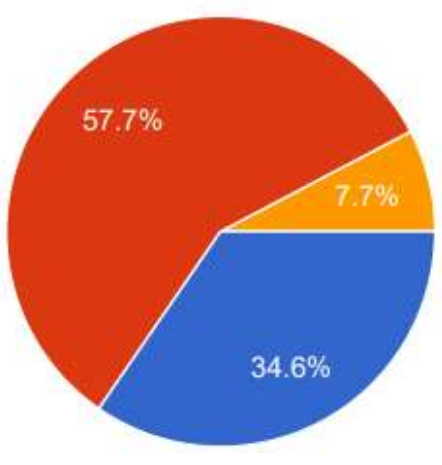

Sim, completamente.

Parcialmente motivado.

Não me senti motivado.

Fonte: Autores.

De acordo com a Figura 3, 34,6\% assinalaram sentir-se completamente motivados; 57,7\% sentiram-se parcialmente motivado e 7,7\% não sentiram motivação nenhuma. Olhando para os dados, significa que cada um deles tem a sua própria responsabilidade para com a atividade que escolheu. Na verdade, há muitos alunos que se concentram apenas em seu propósito secundário, em vez de em seu foco principal de estudar.

Um tipo de atividade para os alunos que pode aumentar sua cooperação e aumentar sua responsabilidade são os jogos como o BeerGame. Um jogo simples pode ser capaz de melhorar a cooperação e habilidade social do membro; praticar a comunicação; e para melhorar a gestão emocional, conforme destacado por Silva (2016).

Foi perguntado se após a apresentação da interface do BeerGame estes sentiram-se atraídos pelo visual do jogo e, as respostas podem ser observadas na Figura 4.

Figura 4 - Alunos atraídos pelo visual do BeerGame.

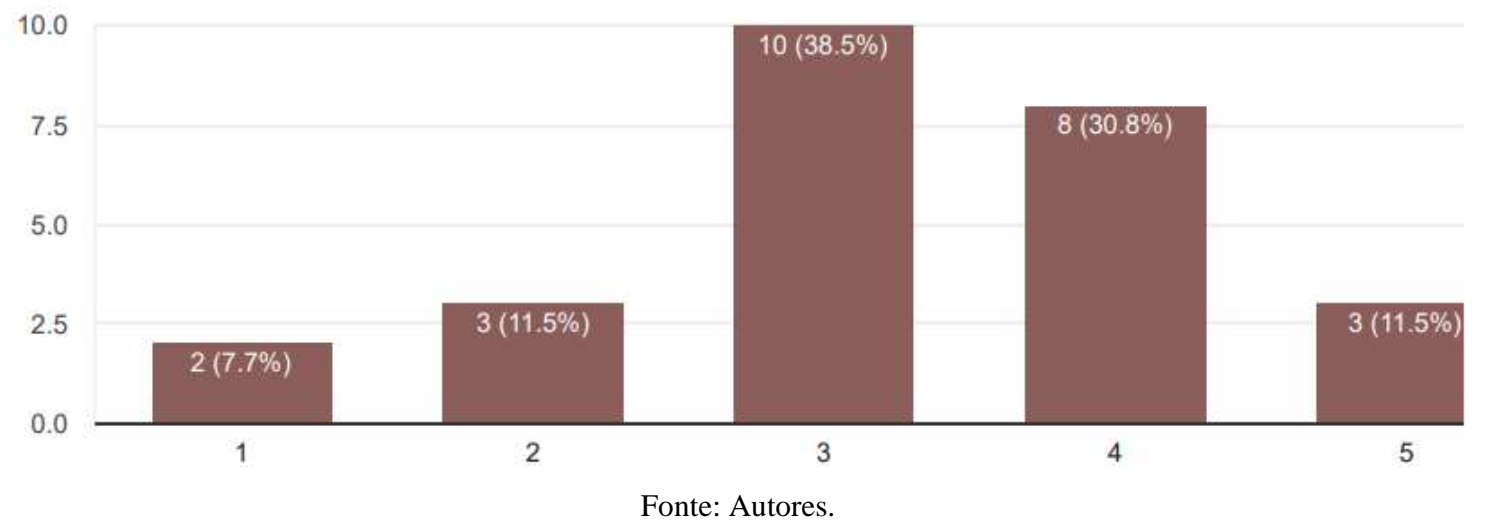

De acordo com a Figura 4, 7,1\% dos alunos sentiram-se pouquíssimo atraídos pelo visual do jogo e desejaram continuar a explorá-lo. E, 11,5\% declaram sentir pouca atração pelo jogo o que reduzir sua vontade de continuar a explorá-lo. Por sua vez, 38,5\% se consideraram indiferentes nesta questão. Entre aqueles que sentiram-se atraídos pelo visual do BeerGame, estavam 30,8\% dos alunos e entre os muito atraídos e com vontade de explorar o jogo, estavam 11,5\% dos alunos. Acredita-se, de acordo com Souza (2019), que o visual nos videogames tenha um papel fundamental na aprendizagem, pois o 
aprendizado acontece com a descrição visual. Este é um fato de grande relevância, pois o visual apresentado inicialmente pode despertar ou não o interesse dos alunos à aprendizagem por meio de jogos.

Após, foi investigado se o conteúdo do BeerGame estava relacionado com os conhecimentos que os estudantes já possuíam (Figura 5).

Figura 5 - Motivação em relação aos conteúdos após a dinâmica.

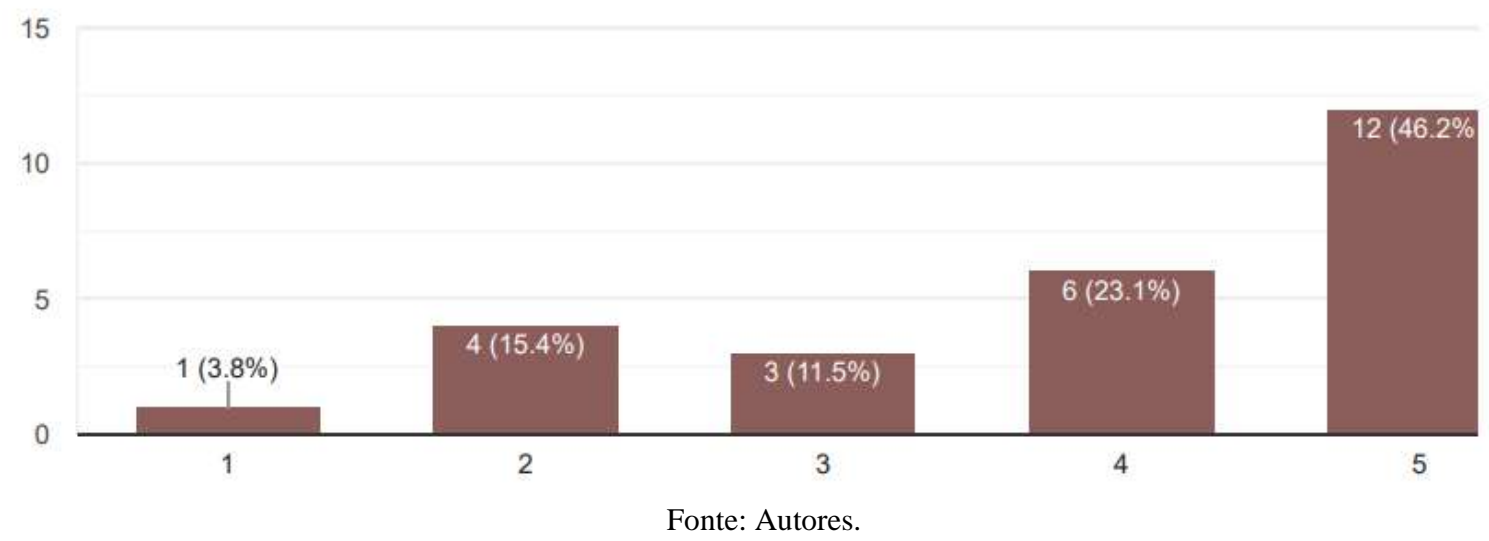

Conforme as respostas obtidas e apresentadas na Figura 5, a maioria dos alunos consideraram que os conteúdos estavam de acordo com seus conhecimentos, sendo esta posição representada por 23,1\% e 46,2\% respectivamente. De acordo com Brown, Collins e Duguid (1989), assim como as ferramentas podem ser adquiridas sem o conhecimento de como usá-las, os alunos também podem memorizar algoritmos e fórmulas sem uma compreensão clara de seu uso específico e aplicações em problemas. Em contraste, as pessoas que usam ferramentas desenvolvem ativamente uma compreensão rica das próprias ferramentas e de sua usabilidade, podem aproveitar melhor os conhecimentos adquiridos e estabelecer interrelações entre diversas disciplinas. Nas palavras dos autores, "Aprender e agir são curiosamente indistintos, aprender sendo um processo contínuo, ao longo da vida, resultante da atuação em situações" (Brown et al, 1989, p.33). Assim, a atividade e as situações tornam-se parte integrante do processo de aprendizagem e cognição (Maciel, Maciel \& Amorim, 2020), dando à cognição sua natureza "situada" e possibilitando que o aprendizado seja construído de forma gradativa (Hermann, Coqueiro \& Pacheco, 2020).

Foi questionado aos alunos se após a aula prática utilizando o BeerGame, o conteúdo trabalhado em sala de aula tornou-se mais atrativo e sentiram-se mais motivados a aprender sobre a matéria estudada (Figura 6).

Figura 6 - Alunos motivados a participar da dinâmica.

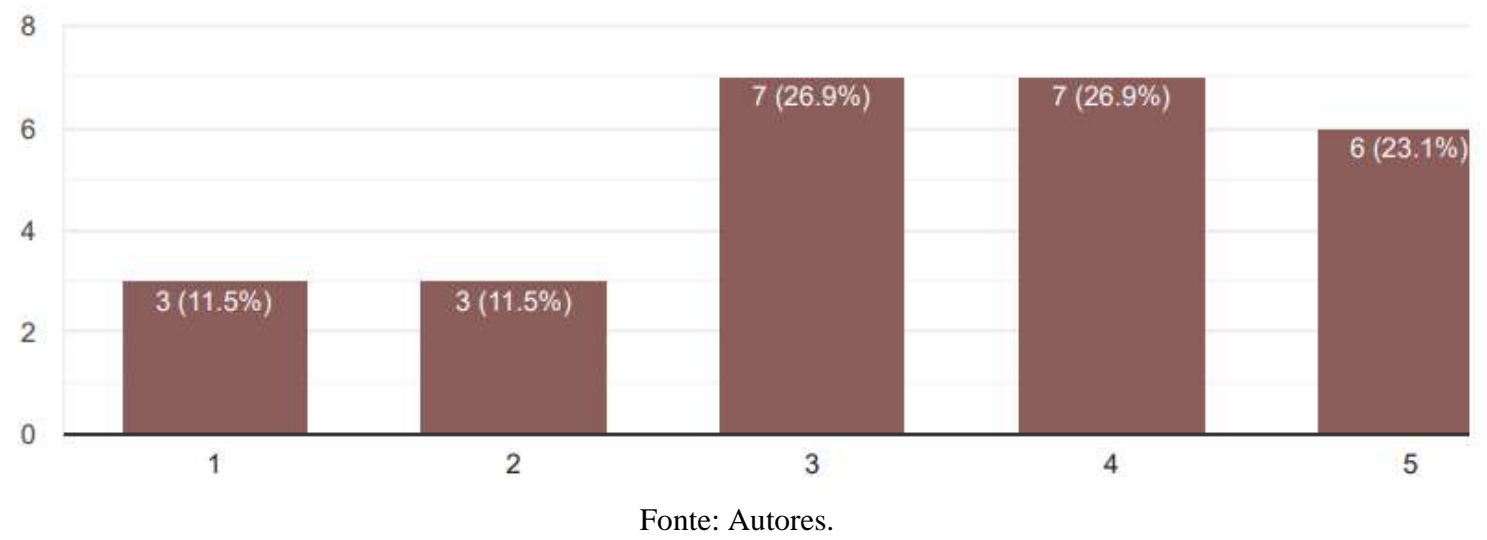


De acordo com a Figura 6, 23\% dos alunos não se consideraram motivados, mesmo após a aula prática. Para 26,9\%, a aula prática foi indiferente para sua motivação. Entretanto, 26,9\% assinalaram ter sentido-se motivados a participar da dinâmica e, 23,1\% consideraram-se muito motivados. Os alunos podem jogar alguns jogos com diferentes objetivos, como integrar valores cooperativos e responsabilidade em sua vida, resolução de problemas, aprendizado mais facilitado, entre outros, (Hayashi, 2020). Existem muitos jogos diferentes para aprender, mas aqui os jogos são desenvolvidos de certas maneiras que fornecem valores de trabalho em equipe e responsabilidade dentro deles conforme destacado por Souza (2019).

Ao buscar conhecer a visão dos alunos quanto ao aproveitamento do BeerGame no estudo de outras disciplinas, temse os dados apresentados pela Figura 7.

Figura 7 - Visão dos alunos quanto ao aproveitamento do BeerGame.

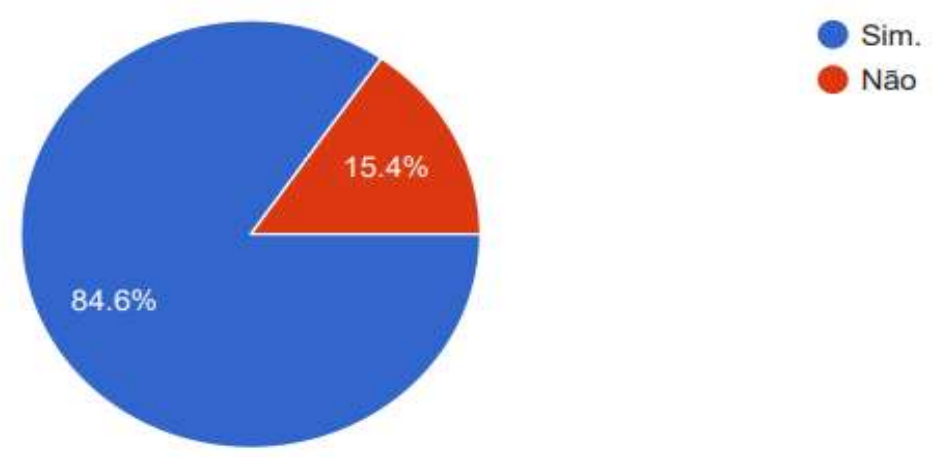

Fonte: Autores.

Conforme a Figura 7, 84,6\% assinalaram que sim e, 15,4\% não. A premissa básica da cognição situada é que toda aprendizagem é contextual e dependente das circunstâncias reais e imediatas (Silva, 2013). Assim, aprendizagem acontece devido à interação entre o indivíduo e o meio ambiente e, diante dos resultados obtidos, verificou-se que, a maior parte dos alunos considerou que o jogo foi importante para o estudo de outras disciplinas.

Entre os alunos que responderam que o BeerGame pode ser aproveitado na aprendizagem de outras disciplinas, entre as mais citadas estão: logística e produção; estatística; saúde e segurança do trabalho, especialmente se for voltada para a análise postural no ambiente de trabalho; gestão de estoque, produção e logística; e na disciplina de Administração da Produção, que foi vista no ano anterior e, com o conhecimento teórico, associado à prática do jogo, os conteúdos foram melhor esclarecidos.

Perguntou-se aos alunos se ao utilizarem o BeerGame, eles consideraram como sendo vantagem o uso do jogo para o estudo na disciplina (Figura 8). 
Figura 8 - Vantagens na utilização do BeerGame.

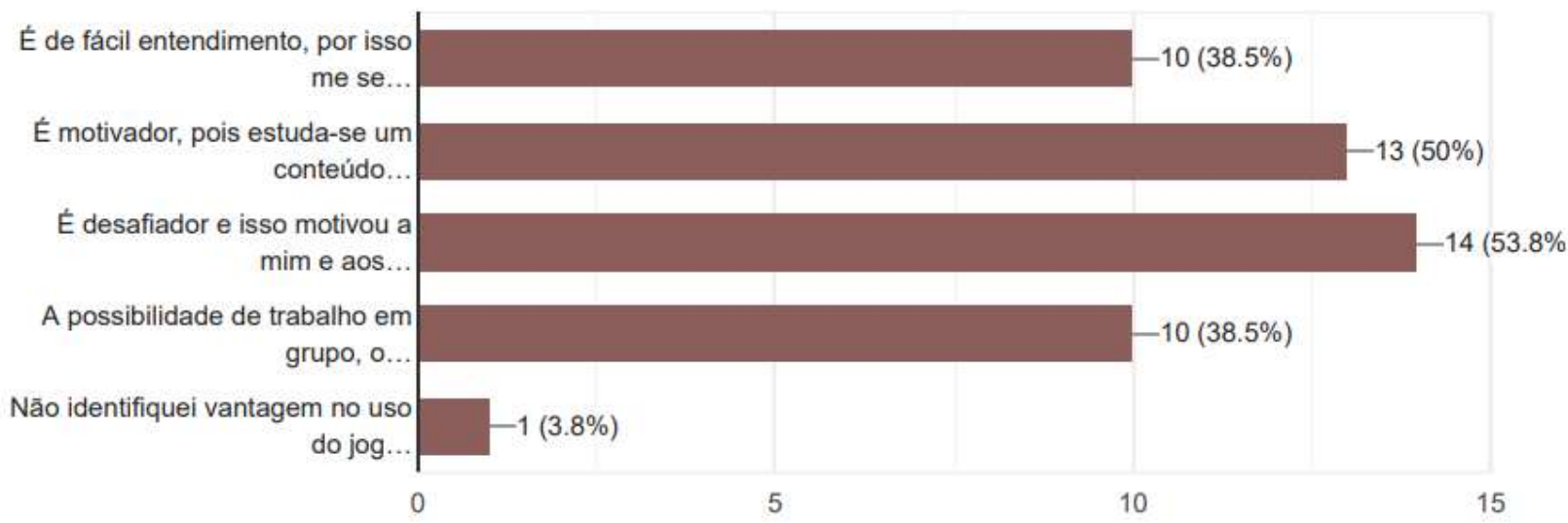

Fonte: Autores.

Conforme a Figura 8, para 38,5\% dos estudantes, o jogo facilitou o entendimento da disciplina; $50 \%$ assinalaram ser um jogo motivador, pois aborda o conteúdo já estudado; 53,8\% consideraram o jogo desafiador e, isso foi um elemento capaz de motivar quase todos os alunos. Para 38,5\% o jogo ainda tem a possibilidade de desenvolver trabalhos em grupo. E, para $3,8 \%$ o jogo não possibilitou identificar nenhum tipo de vantagem quanto ao seu uso para o estudo da disciplina (Figura 8). Em alguns jogos, os jogadores são capazes de fazer a conexão entre os conceitos aprendidos em sala de aula e as aplicações reais desses conceitos. De acordo com Garcia (2017), os jogos integram o aprender e o fazer, além disso, os mundos dos jogos também oferecem aos jogadores a oportunidade de desenvolver habilidades de monitoramento metacognitivo e discernir padrões em eventos e descobrir relacionamentos ocultos. As situações e eventos do jogo também estimulam o pensamento crítico e as habilidades de resolução de problemas, não apenas em alunos, mas também em profissionais adultos.

Após, foi questionado se os textos de feedback dos alunos depois da realização das atividades e os comentários durante a realização do jogo geraram recompensas pelo esforço aplicado durante o jogo (Figura 9).

Figura 9 - Auto compreensão do aluno durante a dinâmica.

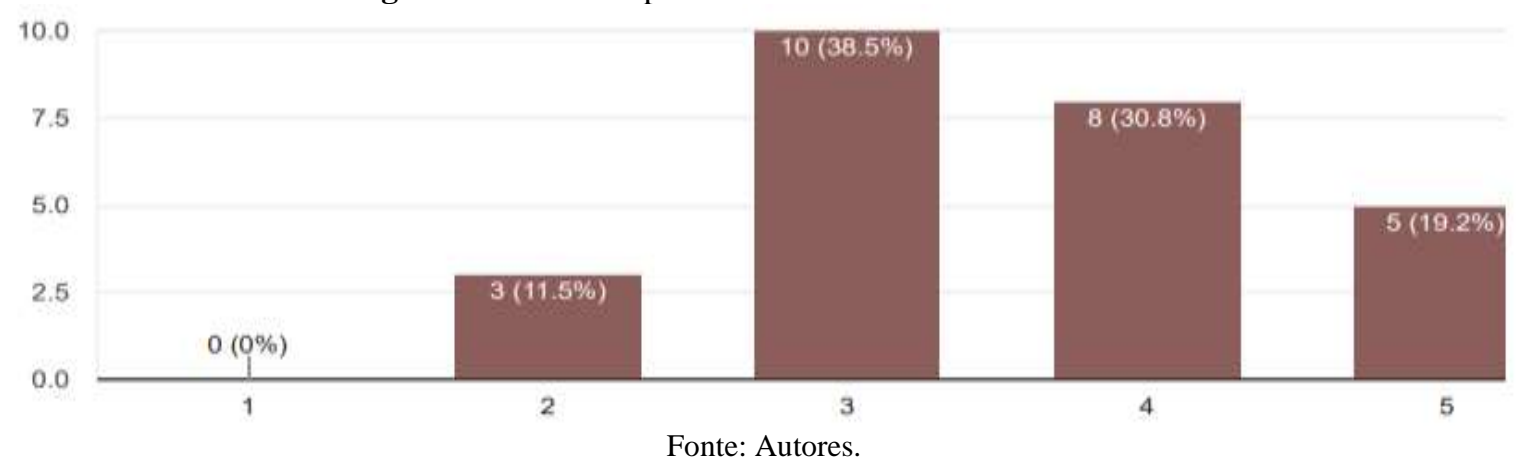

De acordo com a Figura 9, 11,5\% dos participantes tiveram uma autocompreensão pouco significativa. 38,5\% não tiveram sua autocompreensão influenciada. No entanto, para 30,8\% sua autocompreensão foi satisfatória e, 19,2\% consideraram sua autocompreensão muito satisfatória. Entre as principais causas deste resultado está o fato de que alguns alunos têm menos responsabilidade em realizar sua tarefa principal, tanto como alunos quanto como agentes de mudança. Existem alguns alunos que se concentram apenas em seus estudos, enquanto outros participam das dinâmicas propostas com maior interesse, uma vez que desejam expressar seu interesse e talento. Além disso, existem alguns alunos que aderem a esse tipo de dinâmica tendo como objetivo buscar estratégias que possam potencializar sua capacidade de aprender, mesmo em situações diferentes daquelas apresentadas no cotidiano escolar (Silva, 2013). 
Foi questionado se o entendimento sobre o conteúdo estudado aumentou gradualmente à medida em que trabalharam no jogo BeerGame (Figura 10).

Figura 10 - Alunos motivados a participar da dinâmica.

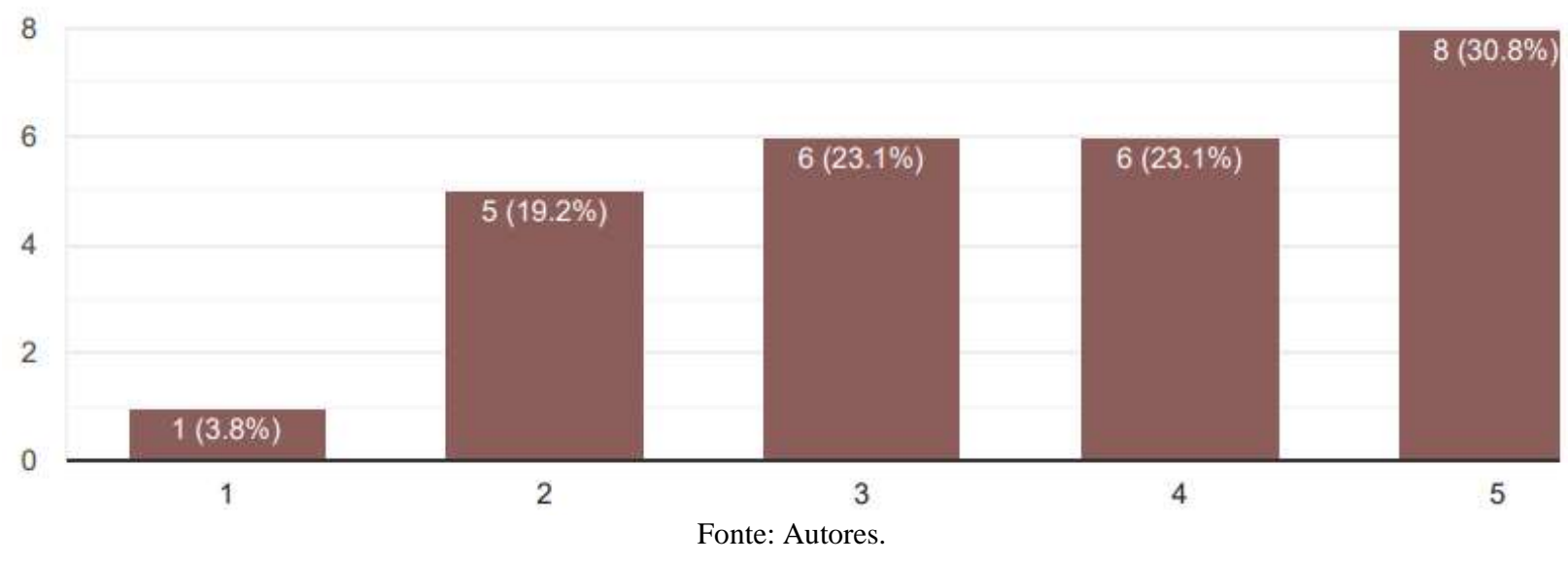

De acordo com a Figura 10, para a maioria dos alunos 23,1\% e 30,8\% a dinâmica do jogo fez com que se sentissem motivados ou muito motivados respectivamente a participar da dinâmica proposta. Tal resultado pode ser reflexo da predisposição dos alunos para enfrentar esses desafios, precisamos desenvolver 'simuladores de gerenciamento' criando ambientes de aprendizagem que motivem, que forneçam aulas vivenciais e cognitivas, que comprimam o tempo e o espaço para que os alunos possam experimentar as consequências de longo prazo de suas ações (Garcia, 2017).

Foi analisada a percepção dos alunos quanto à sua própria evolução no trabalho como BeerGame em sala de aula (Figura 11).

Figura 11 - Evolução dos alunos durante a participação da dinâmica.

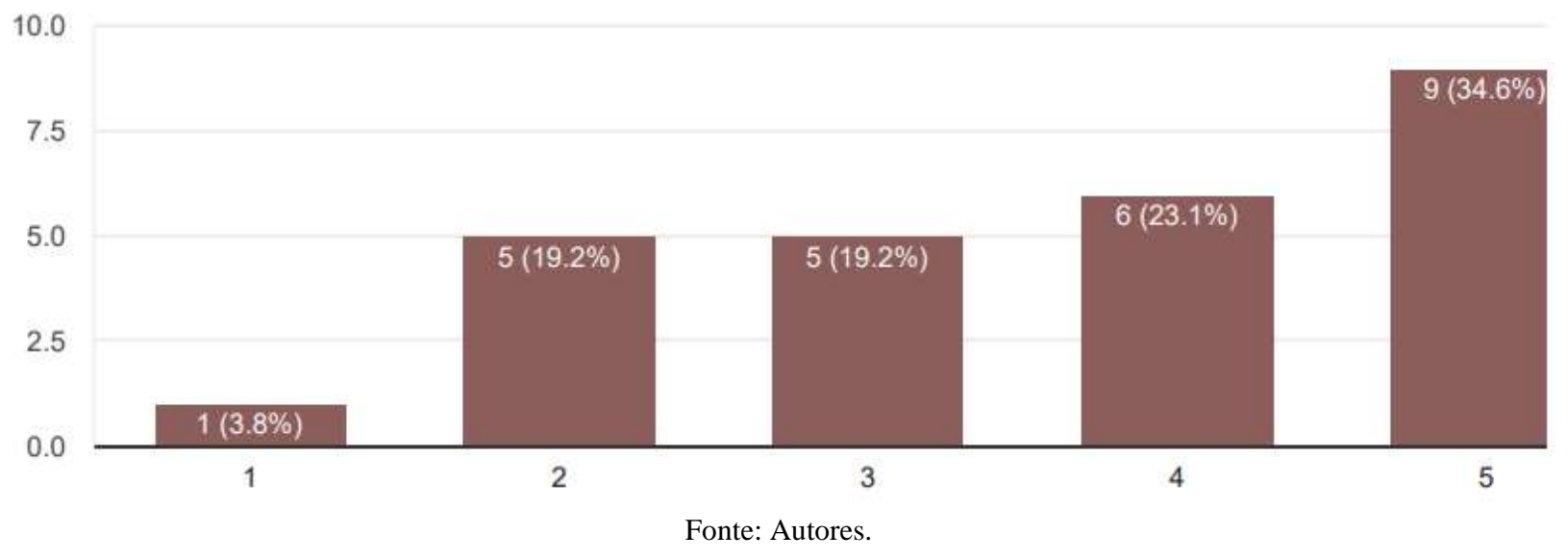

De acordo com a Figura 11, 23,1\% consideraram que houve uma evolução em seu trabalho no jogo, enquanto 34,6\% assinalaram ter apresentando uma evolução significativa durante a dinâmica proposta pelo jogo. Por sua vez, 3,8\% consideram não ter alcançado nenhuma evolução. 19,2\% consideram que houve uma evolução pouco significativa e, $23,1 \%$ não vislumbraram evolução nem retrocesso no seu trabalho durante a dinâmica do jogo. Os resultados indicam que, a existência de limitações de informação implica que os jogadores não consigam coordenar suas decisões ou planejar conjuntamente a estratégia, ainda que o objetivo de cada equipe seja minimizar os custos totais. Como em muitos ambientes da vida real, o problema de otimização global deve ser fatorado em subproblemas distribuídos por toda a organização, os alunos que 
conseguiram evoluir no jogo, perceberam que podem evoluir além do que é determinado pelo ambiente educacional, conforme destacado por Bellomusto (2018).

A percepção dos alunos quanto à própria competência ao término da dinâmica do BeerGame é representada na Figura 12.

Figura 12 - Grau de competência percebido pelos alunos após a dinâmica.

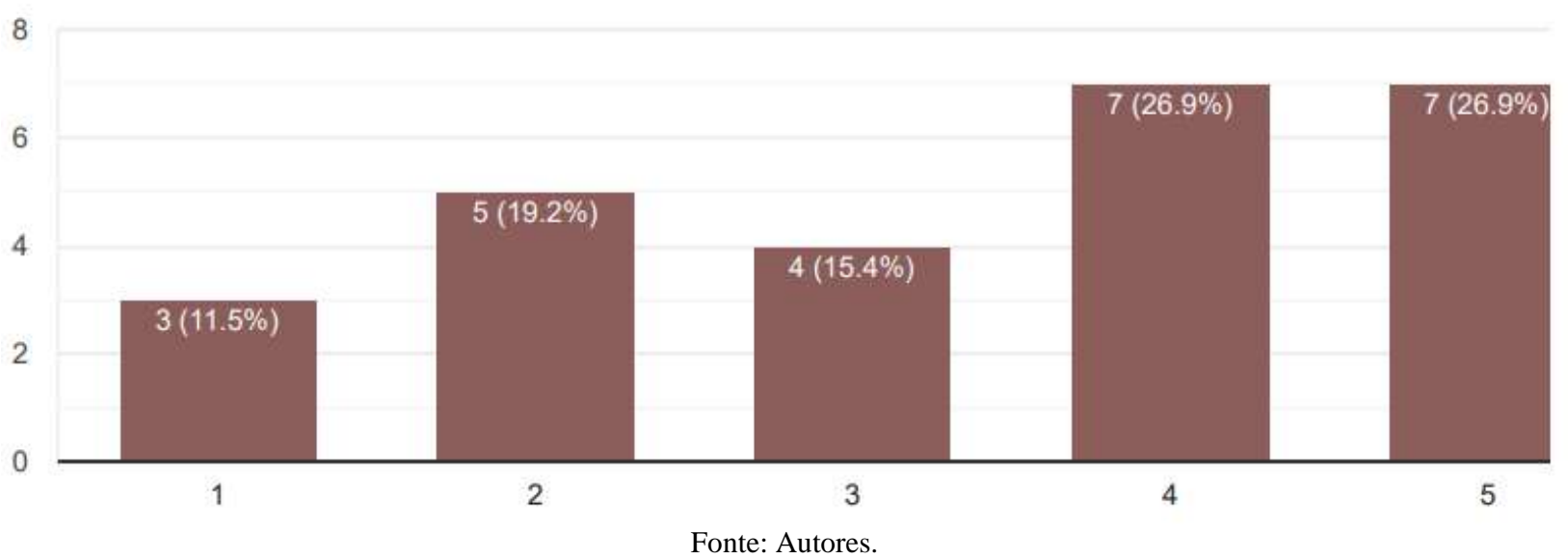

Conforme a Figura 12, 11,5\% sentiram-se sem competência para o trabalho com o jogo; 19,2\% consideraram-se pouco competentes. 15,4\%, estão indiferentes nesta questão. Entretanto, entre aqueles que julgaram-se competentes ou muito competentes, estão respectivamente $26,9 \%$. Conforme Lira (2020), tal resultado foi gerado pois, alguns alunos ainda parecem individualistas no processo de aprendizagem. Alguns alunos terminam suas tarefas sozinhos, mas há outros que trabalham em grupo. Na verdade, cada meta de aprendizagem pode ser alcançada por eles, mas tem um valor diferente. Fazer algumas atribuições em grupo tem valor diferente e obtém melhor resultado.

Foi questionado se durante a dinâmica do jogo os estudantes puderam auxiliar algum colega (Figura 13).

Figura 13 - Alunos que puderam auxiliar seus pares durante a dinâmica.

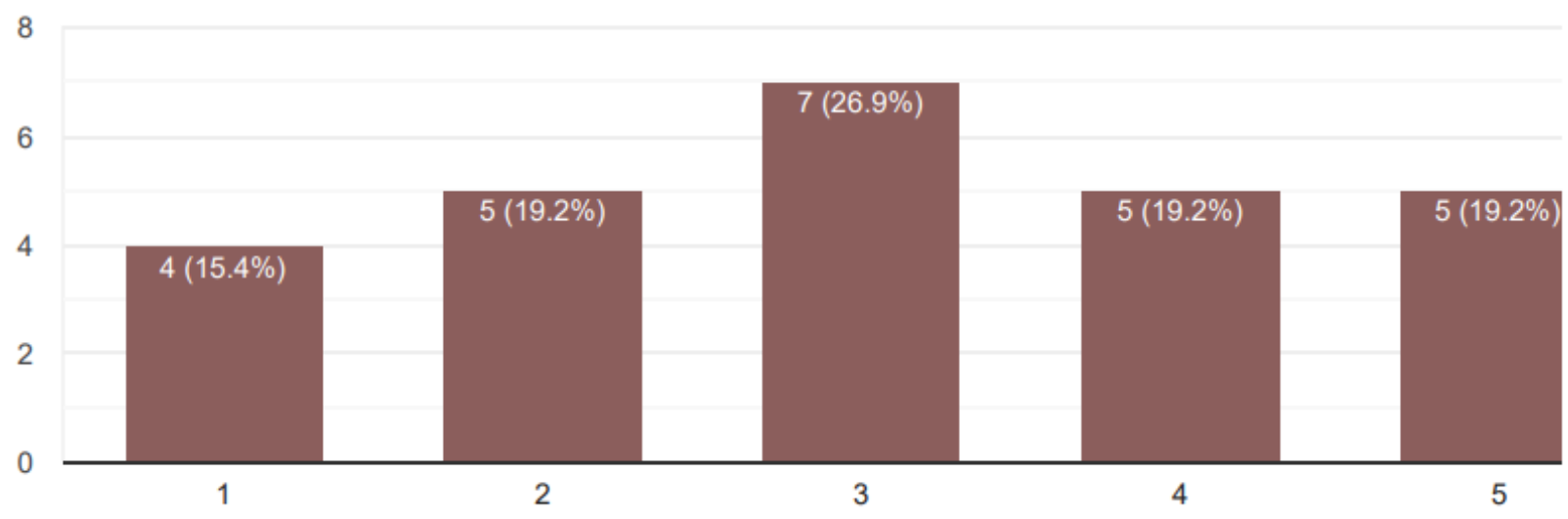

Fonte: Autores.

Conforme a Figura 13, 19,2\% conseguiram auxiliar de maneira satisfatória ou muito satisfatória alguns colegas. Em contrapartida, 26,9\% não se preocuparam em auxiliar seus colegas. 19,2\% prestaram pouca ajuda aos colegas e 15,4\% não conseguiram auxiliar seus pares durante o jogo. Com base no resultado obtido, Silva (2016) cita que humanos são criaturas sociais. Da mesma forma, os alunos, que definitivamente incluem também as criaturas sociais, não podem viver sozinhos. Eles precisam de outros para atingir seu objetivo de aprendizagem. Além disso, não conseguirão administrar suas atividades por 
conta própria, pois precisarão da ajuda de seus amigos para sustentar seus estudos, como aconteceu com 15,4\% dos alunos. Como alunos que desejam se atualizar, eles precisam de seus pares para terminar suas próprias atribuições ou seu trabalho em grupo como membros da unidade de classe.

Buscou-se identificar se, após o jogo, os alunos conseguiram reter um número maior de informações relacionadas ao conteúdo (Figura 14).

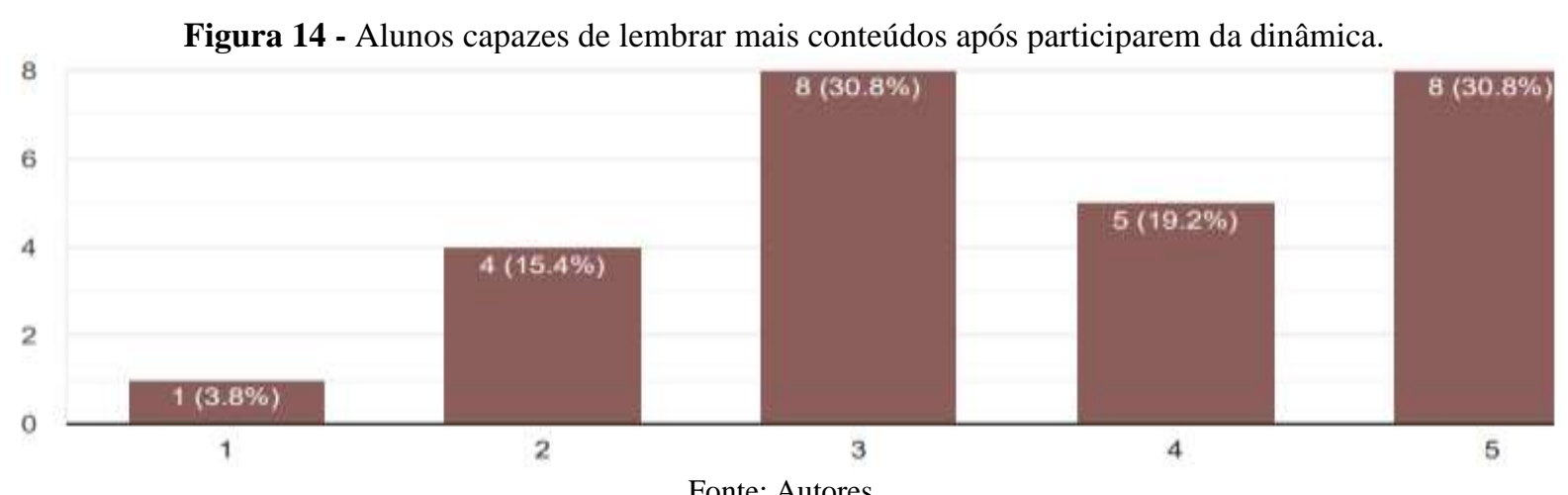

De acordo com a Figura 14, 3,8\% afirmaram não se lembrar dos conteúdos, 15,4\% lembram-se pouco dos conteúdos. Para 30,8\% a capacidade de reter conteúdo não foi alterada. Entre aqueles que consideraram ter ampliado sua capacidade de lembrar de mais informações relacionadas à disciplina trabalhada estão 19,2\% e, 30,8\% consideraram que sua capacidade de lembrar dos conteúdos foi muito beneficiada. O jogo ajuda os alunos a compreender totalmente os benefícios do aumento das comunicações dentro da dinâmica das aulas (Pinheiro et al., 2016). Os alunos que afirmam que, embora tenham "meio que compreendido os benefícios de uma melhor comunicação nas aulas em sala de aula, puderam verificar que o jogo tornou os benefícios dessa comunicação" óbvios para qualquer pessoa".

Por fim, questionou-se se os alunos voltariam a fazer uso do BeerGame e se indicariam o game para outros colegas e professores (Figura 15).

Figura 15 - Alunos que voltariam a utilizar o BeerGame.

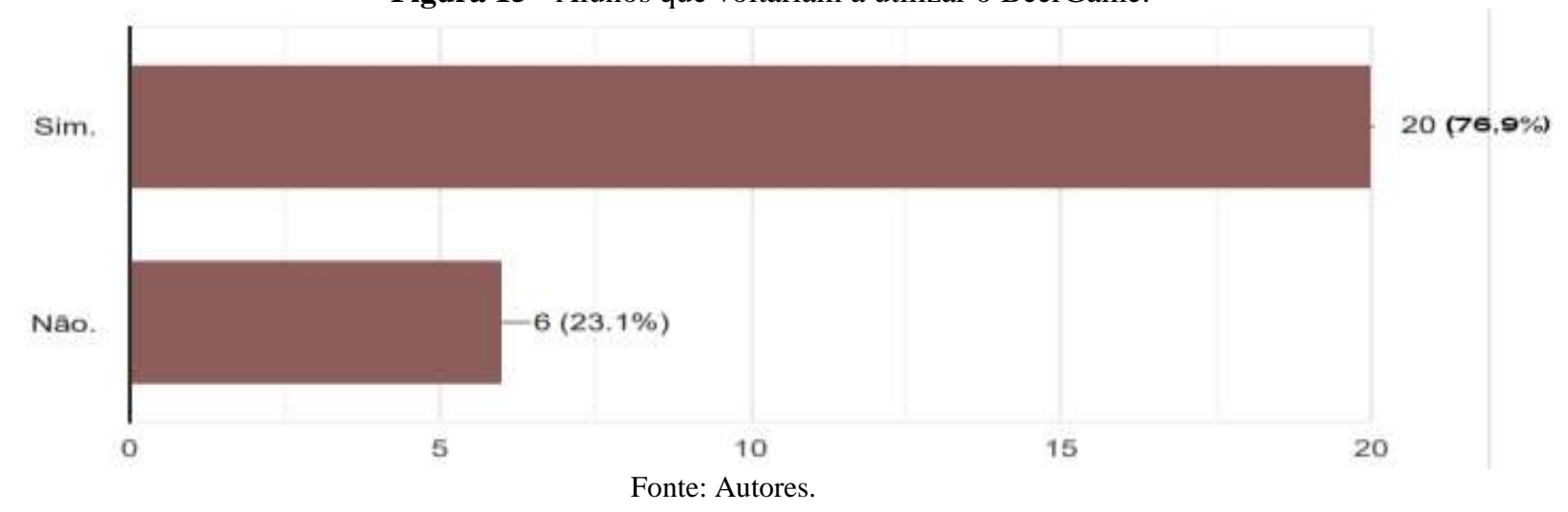

Conforme a Figura 15, 76,9\% responderam que sim, e 23,1\% não indicariam o jogo. Os resultados a esta questão indicaram que, mesmo com a existência de obstáculos ao aprendizado, a maior parte dos alunos conseguiu construir modelos mentais por meio dos quais puderam elaborar sua compreensão da realidade. Assim, conforme Souza (2019), o jogo forneceu uma experiência vívida com um sistema complexo, onde os jogadores puderam ver como os resultados coletivos de decisões individualmente sensíveis a conexão entre a estrutura de um sistema e a dinâmica que ele gera e, tal fato fez com que eles 
pudessem expressar seu desejo de utilizar ou não o BeerGame.

Ao término do questionário, foi dada a liberdade aos alunos para darem sugestões ou críticas sobre o BeerGame quanto à sua forma de apresentação e trabalho em sala de aula. E, entre as sugestões, foram propostas a inserção de animações no jogo; otimização das instruções acerca das operações; mudança no layout da página de modo a tornar o jogo mais interativo.

No tocante ao trabalho realizado em sala de aula, o aluno destacou que, na primeira parte da prática, na primeira semana do jogo, as informações ficam um pouco confusas. Dessa forma é recomendável ter uma explicação geral do jogo antes de ir para a página principal, como por exemplo da cadeia de suprimentos e do jogo em geral."

\section{Considerações Finais}

Ao buscar analisar o uso desta tecnologia em sala de aula, avaliando o comportamento, a atratividade, compreensão e entendimento do aluno pelo assunto abordado por meio do BeerGame, os alunos tiveram a oportunidade de enfatizar, investigar e analisar as ineficiências da cadeia de suprimentos, bem como o efeito dos vieses dos tomadores de decisão.

No decorrer do jogo os alunos verificaram que o desempenho de curto e longo prazo no jogo de distribuição de cerveja, pode ter comportamento caótico dependendo das heurísticas utilizadas pelos tomadores de decisão. Além disso, foi possível observar com o auxílio do BeerGame, a rapidez com que o sistema atinge um estado estacionário (se o atinge). Os alunos puderam verificar ainda que ao ignorar a linha de abastecimento, deixando pedidos pendentes, leva-se ao efeito chicote. Entre outros resultados obtidos na dinâmica do jogo, foi possível constatar que o desempenho de curto prazo de uma cadeia de suprimentos não é um preditor do desempenho de longo prazo, mesmo quando os tomadores de decisão reconhecem totalmente os pedidos pendentes.

Os resultados da simulação e as implicações práticas foram discutidos e, observou-se que nem todos os alunos estavam aptos e/ou motivados à prática, este pode ser um fator limitante no seu desempenho ao final do jogo. É válido ressaltar que os resultados obtidos podem ser usados para projetar novos programas de logística e produção; estatística; gestão de estoque, produção e logística; e na disciplina de Administração da Produção, para e redesenhar e atualizar os programas existentes. Além disso, os resultados indicam que todas as habilidades individuais são altamente avaliadas no que diz respeito à importância.

No entanto, ainda há muitos alunos que percebem suas classificações de desempenho inferiores aos demais colegas, sendo este um indicativo entre o nível de desempenho e a importância de uma habilidade específica capaz de indicar sua força ou fraqueza para habilidades como "gestão de conflitos", "gestão de mudanças" e "conhecimento das diferenças de infraestrutura"; "Planejamento de distribuição" e "gerenciamento de armazenamento"; "Integração do fluxo de informação"; "Conhecimento das cadeias de suprimentos", "logística" dentre outras disciplinas.

É possível observar alguns benefícios que o jogo proporciona para os professores e instituições: metodologicamente superior a outros tipos de recursos; a possibilidade de exibir e explicar vários conceitos de negócios; totalmente personalizável e flexível sobre os objetivos de aprendizagem; ferramentas automatizadas e controle total do andamento do curso; permite o trabalho interdisciplinar; ajuda a integração é um conceito teórico abstrato com prática; possui alguns relatórios de análise e apoio ao professor; adapta-se a diferentes finalidades; estimula o trabalho em equipe; baixo custo de aquisição / implantação.

Em contrapartida, os benefícios para os alunos são: a diversão do jogo promove a aprendizagem; o processo inclui várias habilidades; a experiência de aprendizagem é mais eficaz; a compreensão sistemática de conceitos complexos (finanças, economia, gestão, etc.); competição entre pares estimula o processo de aprendizagem; simulação dinâmica como a situação real na empresa; feedback contínuo por meio de relatórios disponíveis; integração entre teoria e prática; promoção do raciocínio analítico e do planejamento adequado; treinamento para tomada de decisão ao longo da rodada.

Espera-se que este estudo contribua com outras pesquisas nesta temática e, para abordagens futuras, sugere-se que os 
docentes incluam outras variáveis na pesquisa, a fim de identificar outros fatores de influência na aplicação da atividade.

\section{Referências}

Batista, M. S., \& Baldissera, T. A. (2011). Uso de tecnologias em sala de aula:um estudo de caso com alunos e professores dos anos finais do ensino fundamental no município de Santiago- RS. Trabalho de Conclusão de Curso. Universidade Federal de Santa Maria, Santa Maria.

Bellomusto, M. P. (2018) Aplicação de métodos ativos de ensino aprendizagem na disciplina de logística empresarial do curso de graduação em Engenharia de Produção da UFSC. Monografia. Universidade Federal de Santa Catarina. Florianópolis, Santa Catarina, Brasil.

Bernardi, S. T. (2010). Utilização de softwares educacionais nos processos de alfabetização, de ensino e aprendizagem com uma visão pedagógica. Revista de Educação do Ideau, Caxias do Sul, 5, (10), 15p.

Brown, J. S., Collins, A., \& Duguid, P. (1989). Situated Cognition and the Culture of Learning. Educational Researcher, 18(1), 32-42.

Calvalcanti, E. S. et al.(2017). O uso de software educativo no ensino aprendizagem da disciplina de língua portuguesa. Anais do EDUCERE-Congresso Nacional De Educação, XII, Curitiba,Brasil, 10836- 10850.

Carmo, J. R., Paciulli, S. O. D. \& Nascimento, D. L. (2020) O impacto do uso de Tecnologias de Informação e Comunicação (TIC's) por docentes dos Institutos Federais localizados em Minas Gerais em um contexto de pandemia. Research, Society and Development, 9(10), p. e5199108940.

Chopra, S., \& Meindl, P. (2001). Supply Chain Management: Strategy, Planning, and Operation. Prentice Hall.

Cunha, E., \& Lima, R. (2004). O Jogo da Cadeia de Suprimentos: uma proposta econômica e prática para a simulação de conceitos logísticos em sala de aula. Anais do Encontro nacional de engenharia de produção, ABEPRO. Florianópolis-SC, Brasil, 24.

Filho, N. N., \& Matos, E. L. M. (2010). A arte de envolver o aluno na aprendizagem de ciências utilizando softwares educacionais. Educar em Revista, v.2, p. 121-136. https://www.scielo.br/scielo.php?script=sci_arttext\&pid=S0104-40602010000500007

Fioriolli, J. C., \& Fogliatto, F. S. (2009). Modelagem do efeito chicote em ambientes com demanda e lead time estocásticos mediante uma nova política de tratamento dos excessos de estoque. Revista Produção, 19(1), 27- 40.

Gabriel, M. (2013). O professor está preparado para uma classe digital? https://desafiosdaeducacao.grupoa.com.br/professor-esta-preparado-para-uma-classedigital/.

Garcia, J. R., et al. (2017). Proposição de aplicações de jogos para o ensino da Gestão da Produção e Logística nos cursos de Engenharia. Anais do Congresso Brasileiro de Ensino de Engenharia, XLI, Joinville, UDESC.

Hayashi, C. (2020) Tecnologias digitais na Educação a Distância: fases, modelos, plataformas e ferramentas. Research, Society and Development, 9(10), p. e8079109295.

Hermann, W, Coqueiro, V. S., \& Pacheco, P. S. (2020). Um panorama das publicações de quatro periódicos da área de educação de matemática a respeito de jogos como recursos didáticos para o ensino de matemática. Research, Society and Development, 9(10), e6639109002.

Koche, J. C. (2011). Fundamentos de metodologia científica. Vozes.

Leite, L. S. Tecnologia educacional: descubra suas possibilidades na sala de aula. (5a ed.), Vozes.

Lira, P. H. G. (2020). O uso de jogos em sala de aula no ensino de logística empresarial. 2020. 22 f. Trabalho de Conclusão de Curso. Universidade Estadual da Paraíba, Patos.

Maciel, K. A., Maciel, K. A., \& Amorim, L. S. (2020). Metodologias de avaliação empregadas no curso superior de tecnologia em telemática no Instituto Federal do Ceará (IFCE) - Campus Tauá: análise comparativa. Research, Society and Development, 9(10), e4639108731.

Martinez-Moyano, I., Rahn, J., \& Spencer, R. (2005). The Beer Game: Its History and Rule Change. http://www.systemdynamics.org/conferences/2005/pro ceed/papers/MARTI473.pdf

Martins, G. A., \& Theóphilo, C. R. (2009). Metodologia da investigação científica para ciências sociais aplicadas. (2a ed). Atlas.

Pereira, A. S., Shitsuka, D. M., Pereira, F. J., \& Shitsuka, R. (2018). Metodologia da pesquisa científica. UFSM.

Pinheiro, E. V. et al. (2016) Um modelo de simulação do jogo da cerveja para o estudo do impacto da informação na mitigação do efeito chicote na cadeia de suprimentos: ferramenta para apoio educacional em gestão da cadeia de suprimento. GEPROS. Gestão da Produção, Operações e Sistemas, 11(2), 53-65.

Scattone, C., \& Masini, E. F. S. O software educativo no processo de ensino-aprendizagem: um estudo de opinião de alunos de uma quarta série do ensino fundamental. Revista da Associação Brasileira de Psicopedagogia, 24, (75), 240-250, 2007. https://www.revistapsicopedagogia.com.br/detalhes/333/osoftware-educativo-no-processo-de-ensino-aprendizagem--um-estudo-de-opiniao-de-alunos-de-uma-quarta-serie-do-ensino-fundamental.

Silva, R. da S. (2016). Uso de atividades gamificadas no ensino técnico profissional: uma proposta pedagógica. Dissertação do Mestrado em Gestão Educacional - Universidade Vale do Rio dos Sinos, São Leopoldo.

Silva, R. S. (2013). Aplicação da lógica MRP/DRP no Beer Game através do desenvolvimento de uma planilha como ferramenta de capacitação. Trabalho de Conclusão de Curso de Engenharia de Produção da Escola Politécnica da Universidade Federal do Rio de Janeiro, Rio de Janeiro. 
Research, Society and Development, v. 10, n. 3, e55110313716, 2021

(CC BY 4.0) | ISSN 2525-3409 | DOI: http://dx.doi.org/10.33448/rsd-v10i3.13716

Souza, M. C. et al. (2019). Beer Game: jogo empresarial como método de aprendizagem no ensino superior. Brazilian Journal of Development, 5(12).

Tajra, S. F. (2001) Informática na educação. (6a ed), Érica.

Toleto, B. S. (2014). O uso de softwares como ferramenta de ensino-aprendizagem na educação do ensino médio/técnico no Instituto Federal de Minas Gerais. Dissertação do Mestrado Profissional em Sistemas de Informação e Gestão do Conhecimento - Universidade FUMEC, Belo Horizonte-Minas Gerais.

Titton, L. A. (2006). Jogos de Empresas: decisões de carteiras em um jogo de bancos. Dissertação do Mestrado em Administração - Universidade de São Paulo, São Paulo. 